Anales de Literatura Hispanoamericana

ISSN-e: 1988-2351

\title{
La orfandad de Victorio Ferri, un relato gótico de Sergio Pitol
}

\author{
León Guillermo Gutiérrez ${ }^{1}$
}

Resumen. El artículo analiza el primer relato escrito por Sergio Pitol, "Victorio Ferri cuenta un cuento", en 1958, inscrito dentro de lo que se podría denominar relato gótico.

Palabras clave: Sergio Pitol; cuento; género gótico.

\section{[en] The Orphanhood of Victorio Ferri, a Gothic Tale by Sergio Pitol}

\begin{abstract}
The article analyses the first story written by Sergio Pitol, "Victorio Ferri cuenta un cuento", in 1958, which is part of what could be called a gothic tale.
\end{abstract}

Keywords: Sergio Pitol; story; gothic genre.

Cómo citar: Gutiérrez, L.G. (2020) La orfandad de Victorio Ferri, un relato gótico de Sergio Pitol, en Anales de Literatua Hispanoamericana 49, 219-225.

Transcurría el año de 1956 cuando, a causa de un desamor, Sergio Pitol decidió refugiarse en la lectura en el pequeño poblado de Tepoztlán, ${ }^{2}$ pero el destino le tenía deparado el extraordinario inicio en la aventura de la escritura. En ese poblado se fraguó lo que con el tiempo se convertiría en su pasión y le rendiría frutos insospechados de alegrías y reconocimientos hasta el final de sus días. Comento la anécdota no de forma gratuita, porque el personaje de ese primer cuento "Victorio Ferri cuenta un cuento", ${ }^{3}$ está permeado por el desamor, la soledad y la insanidad mental. Sabemos que la escritura en ocasiones puede servir de catarsis y que el subconsciente es una fuerza que opera de manera extraordinaria. Cuando nos preguntamos cómo o porqué surge en Pitol la imperiosa necesidad de escribir ese primer cuento, nos ayuda Vargas Llosa, quien dice: “¿Por qué necesita el hombre contar y contarse historias? [...] Es una manera de recuperar, dentro de un sistema que la memoria estructura con ayuda de la fantasía, ese pasado que cuando era experiencia vivida tenía el semblante del caos" (1982: 9-10).

Sergio Pitol no escribe su primer relato como simple aficionado. A sus 24 años en su haber están las lecturas de Verne, Stevenson, Dickens, Marcel Proust, Faulkner, Thomas Mann, Woolf, Neruda y Borges. En la entrevista que Pitol le concede a Jorge Luis Herrera para la revista Casa del Tiempo habla sobre su incursión en la escritura:

A los veinticuatro años, en un momento de mi vida en que estaba muy hastiado de todo y sentía la necesidad de alejarme de los grupos en los que me movía. En 1956 me refugié durante dos o tres semanas en una pequeña casa que alquilé en Tepoztlán, un pueblo entonces prácticamente inaccesible. No había luz eléctrica. Era un lugar maravilloso. Me llevé muchos libros; en esa época trabajaba para algunas editoriales como la de Martín Luis Guzmán, haciendo traducciones y dictámenes. El primer día no tuve ganas de hacer nada, sólo leí a Henry James y a Francisco de

\footnotetext{
1 Universidad Autónoma del Estado de Morelos. Cuernavaca. México.

E-mail: leongg@prodigy.net.mx

${ }^{2}$ Mario Muñoz, en "Cuentos de juventud", escribe: "En este refugio donde solía aislarse del tráfago urbano, pasó dos semanas de absoluta entrega a la creatividad, trance que dio por resultado la saga de los Ferri y el mítico espacio de san Rafael. Configuraciones literarias que eran la proyección de sus obsesiones infantiles más recónditas" (2007).

${ }^{3}$ Juan José Arreola, en el número 14, de Cuadernos del Unicornio, el 18 de octubre de 1958, publicó el primero cuento de Sergio Pitol, "Victorio Ferri cuenta un cuento".
} 
Quevedo. El segundo, en la noche, comencé a escribir un cuento inspirado en una historia que le oí a mi abuela cuando era adolescente - mi abuela era muy buena relatora. Tenía muchas lecturas y las historias de su vida eran muy interesantes; todavía me sirven para escribir-. Sin darme cuenta, de repente la historia tomó otro cauce y se convirtió en un cuento. Me percaté de eso hasta muy entrada la noche, casi al amanecer. Al día siguiente desperté tarde y salí a caminar. Regresando a la casa leí lo que había escrito. Luego recomencé a enmascarar el personaje femenino del relato germinal de mi abuela, novelicé la realidad, definí la estructura y lo pulí; deseaba que el lector sintiera una corriente subterránea. Ese fue mi primer cuento. [...] Cuando terminé mi primer libro descubrí que me había liberado de algo que me molestaba; me sirvió para reafirmarme como persona. A los veinticuatro años sentía que no lograba romper con la adolescencia y con algunos lazos del pasado. Durante los siguientes años no tuve ninguna relación con la escritura creativa. No lo necesitaba (Herrera 2009: 46-48).

En el cuento de Sergio Pitol, "Victorio Ferri cuenta un cuento", el encubrimiento de la historia es la misma evidencia que salta a la vista: la ausencia de madre, que también podríamos decir la anulación, porque de manera deliberada se convierte en el fantasma no nombrado, pero que no le exime de su existencia. En las primeras líneas de la narración, en voz de Victorio Ferri, aparece su entorno familiar: el padre, la hermana y el primo José. Se omite la madre hasta más allá de la muerte del protagonista, en la lápida sólo se inscribe el apellido paterno. Ricardo Piglia (2000) señala que la verdadera historia se encuentra en lo no dicho, y es el caso del relato de Pitol. Si nos atenemos a la circunstancia bajo la que fue escrito y los antecedentes del escritor tenemos un hilo conductor. A causa de un desamor se refugia en el poblado de Tepoztlán acompañado de un puñado de libros, y así de repente surge la escritura del cuento de manera febril. Un desamor equivale a un duelo, a un abandono. En muchas ocasiones es en donde se presenta el subconsciente y la impronta del suceso es transferido a un duelo anterior que deja sus huellas indelebles tan fuertes como el suceso acaecido mucho tiempo atrás.

Sergio Pitol siendo niño perdió a su padre, la familia materna fue por ellos a la ciudad de Puebla, al regreso, su madre muere ahogada en un río. Así que fue objeto de una doble pérdida. El personaje del cuento es un niño que narra desde el lecho donde se encuentra postrado a causa de una enfermedad que desconocemos. Sergio Pitol, a partir de la orfandad queda al cuidado de la abuela materna, y la enfermedad del paludismo con frecuencia lo postra en cama durante meses. De todo lo anterior podemos hacer la conjetura de que el escritor mexicano, después de la muerte de su madre, cayó en un estado de perturbación, y sobre todo gran dolor. Mario Vargas Llosa escribió: "Nunca ha dejado de intrigarme y sorprenderme el imprevisible, escurridizo camino que sigue la mente para, escarbando en los recuerdos, apelando a los más secretos deseos, impulsos, pálpitos, 'inventar', una historia” (1982: 11). En el caso del relato de Pitol, están presentes los recuerdos pretéritos en la hacienda de Potrero, Veracruz, y quizás más apremiante el sentimiento de pérdida a causa del rompimiento amoroso. Sucesos que aparecen de forma soterrada para ofrecernos otra historia, la verdadera, la literaria. Sobre el cuento señala Mario Muñoz: "Es el relato emblemático de Sergio Pitol por anticipar varias claves de su obra posterior, como la intensa carga autobiográfica" (1994: 78).

Al primer cuento escrito por Sergio Pitol lo podemos ver desde la perspectiva de Ricardo Piglia cuando escribe sobre "El último cuento de Borges": "Los grandes relatos de Borges giran sobre la incertidumbre del recuerdo personal, sobre la vida perdida y la experiencia artificial. La clave de este universo paranoico no es la amnesia y el olvido, sino la manipulación de la memoria y de la identidad" (2000: 51). Lo que podemos completar con lo señalado por Vargas Llosa: “Ayudados por la memoria y la imaginación, en esas 'ficciones' se encuentran paradójicamente algo semejante y distinto de nosotros. La ficción es el hombre 'completo', en su verdad y en su mentira confundidas" (1982: 10). Las dos tesis nos llevan a considerar que, en esa primera narración de Pitol, no sólo se encuentran enmascaradas las historias que le contaba la abuela, sino la suya propia, la pretérita y la instantánea, donde la memoria es manipulada por el subconsciente. Y cuando hablamos del subconsciente no podemos dejar pasar por alto la relación que ha existido entre literatura y psicoanálisis. Piglia en "Los sujetos trágicos", afirma: "En medio de la crisis generalizada de la experiencia, el psicoanálisis trae una épica de la subjetividad, una versión violenta y oscura del pasado personal" (2000: $58)$. 
A partir de las reflexiones anteriores comenzaremos con el estudio del primer cuento de Sergio Pitol. El relato está estructurado en un largo monólogo de doce párrafos. El título corresponde a la tercera persona, al igual que las últimas cuatro líneas, y que hacen las veces de epílogo. En la edición de Tiempo Cercado, 1959, "Victorio Ferri cuenta un cuento" ocupa el quinto lugar en el índice, y consta de ocho páginas. ${ }^{4}$ El monólogo está a cargo de un varón en el inicio de su adolescencia. Mario Muñoz, dice al respecto: "La primera persona implica una necesidad de acortar la distancia entre el lector y lo narrado, del tal forma que vaya siendo progresivamente envuelto en el punto de vista del narrador, como es el caso de "Victorio Ferri"' (1994: 29). En cuanto a los personajes, aunque tienen un lugar capital el padre y la hermana, pronto nos percatamos de que se trata de una población polarizada: los Ferri, ricos hacendados, y los peones de la hacienda. Y es precisamente en la hacienda el Refugio, de San Rafael, donde se desarrolla la diégesis. Tenemos un tiempo real y un tiempo histórico. El primero re refiere al mes que el protagonista lleva postrado en cama a causa de una enfermedad que desconocemos, y sus recuerdos de los tres últimos años; el segundo es una época anterior al triunfo de la Revolución mexicana, cuando existían las haciendas. La estructura narrativa, además de ser elíptica, se complica por la superposición de planos donde pasado, presente y futuro crean un desequilibrio del discurso. La memoria, la analepsis y el enfático presente producen un continuo fluir de conciencia del narrador enfrentado a una doble batalla, la enfermedad mental que le achacan, y la física que lo amenaza de una muerte inminente. Mario Muñoz, estudioso de la obra de Sergio Pitol, señala que cada texto del autor:

Se caracteriza por una depuración de lo accesorio - la anécdota, la circunstancia histórica, el detalle ambiental - y una internacionalización en los mecanismos de la conciencia que progresivamente constituirán un tiempo y un espacio integrados a partir de la memoria del pasado y la vivencia inmediata del presente (1994: 19).

Ahora veamos como Sergio Pitol con los elementos anteriores construye la historia verdadera, la literaria, en un cuento gótico, ya que en el mismo se encuentran los elementos arquetípicos del género. Para su análisis vamos a seguir, en lo general, las características propuestas por César Fuentes Rodríguez (2007) en su libro Mundo Gótico. ${ }^{5}$

Sergio Pitol hace uso de un narrador que está a cargo del monólogo. ${ }^{6}$ Esta estrategia literaria confiere todo el soporte al único narrador, quien nos introduce a su mundo interior. Desde el principio nos enfrentamos a un discurso un tanto perturbador, en donde la voz narrativa, en un ejercicio de afirmación de identidad y de cordura, de manera contundente dice: "Sé que me llamo Victorio. Sé que creen que estoy $\operatorname{loco}^{7}$ (versión cuya insensatez algunas veces me enfurece, otras solo me divierte)" (Pitol 1959: 63). La asociación con "El corazón delator", de Edgar Allan Poe, y "La casa de asterión", de Jorge Luis Borges, salta a la vista. El cuento de Poe inicia con la voz del protagonista que exclama: "Es cierto. Soy muy nervioso. Terriblemente nervioso. Lo he sido siempre. Pero ¿por qué decís que estoy loco?” (1972: 433). Mientras que el narrador del relato de Borges inicia con las palabras: "Sé que me acusan de soberbia, y tal vez de misantropía, y tal vez de locura. Tales acusaciones (que yo castigaré en su debido tiempo) son irrisorias"

${ }^{4}$ A lo largo de este trabajo se tomará en cuenta la versión de "Victorio Ferri cuenta un cuento", en la edición de Tiempo cercado, de Sergio Pitol. México: Editorial Estaciones, Colección La aventura y el orden, dirigida por José de la Colina, 1959.

${ }^{5}$ Fuentes Rodríguez (2007) considera las siguientes características como las más importantes del relato gótico: narrador; vieja edificación; misterio y suspenso; figura masculina tiránica representada por un noble malvado (seres malignos); erotismo oscuro, sentimientos prohibidos; además de depresión, soledad, confusión psíquica.

${ }^{6}$ Un monólogo interior denominado también corriente de conciencia ("stream of consciousness") ha sido utilizado a partir de E. Dujardin por escritores como J. Yoyce. V. Woolf y W. Faulkner por ejemplo, con el propósito de procurar la impresión de inmediatez al dar cuenta de los procesos psíquicos en su transcurso a través de todo tipo de asociaciones en los distintos grados o niveles de conciencia (lógica, ilógica, consciente, subconsciente) (Beristáin 1995).

${ }^{7}$ Joan Corominas asienta en su Diccionario crítico etimológico castellano e hispánico: "Loco es palabra de uso general en todos los periodos literarios de la Edad Media. Desde el principio se halla en sus dos acs. de 'el que ha perdido la razón' [...] y 'tonto, estulto, imprudente' [...] La naturaleza de los textos medievales hace que la $2^{\text {a }}$. ac. se encuentre con mayor frecuencia. Es posible que ésta sea la etimológica (como lo es en el galorrománico fol, y en el cat. boig), pero no se puede asegurar (s. v. 'loco'). La antigua acepción no ha desaparecido del todo. Apenas en el siglo XIX, en Europa, la creciente intervención médica acentúa la diferencia entre locura e insensatez, ya que se piensa que la segunda no es susceptible de tratamiento. Un término estrechamente relacionado con el anterior es el de 'delirio', proveniente del latín delirare, literalmente 'salirse del surco'. La tierra evoca lo real y sus constricciones; la labor designa el trabajo eficaz y socializado. Apartarse de ellos es delirar, estar loco. El delirio, desvío del espíritu, también tiene las acepciones de sueño, entusiasmo, exaltación” (Montelongo 2010: 91-108). 
(1962: 79). En los tres casos los narradores respectivos señalan al otro de acusarlos de una imputación falsa: la locura que les atribuyen. Los tres inician el discurso refutando tal aseveración. ${ }^{8}$

En palabras de Victorio Ferri, el plural de la afirmación, "Sé que creen que estoy loco", consigna la voz del otro en la acepción del que ha perdido la razón. Y es en el estado de delirio (íntimamente ligado a la locura) del protagonista desde el que construye la narración. Podemos afirmar que Victorio Ferri es un personaje oscuro, arquetipo del género gótico, si consideramos la oscuridad en las acepciones de "Falta de luz para percibir las cosas" y "Falta de luz y conocimiento en las facultades intelectuales o espirituales". Nuestro narrador a lo largo del monólogo oscila entre pensamientos y recuerdos donde la percepción objetiva es puesta en tela de juicio. Las enfermedades que padece hacen a su interior presa de una oscuridad espiritual e intelectual. De tal suerte que tanto en las primeras y última líneas del relato la palabra locura funciona como pinza que aprisiona el discurso entero. El lector desde el principio es seducido por la narración del protagonista, y en ningún momento duda de su veracidad porque asiste a un flujo de consciencia espontáneo. Este acierto de Sergio Pitol, se ajusta a las palabras de Truman Capote: "Hallar la forma correcta para un cuento es sencillamente descubrir la manera más natural de contarlo" ("Truman Capote" 1982: 317). Y esta naturalidad se presenta a través de la perspectiva del narrador que la hace desde una focalización interna. ${ }^{9} \mathrm{La}$ cual también ofrece una información subjetiva, su visión de lo acontecido. Aunque también vemos que en sus afirmaciones silencia o trata de imponer su visión sobre las voces que lo creen loco, y lo que dicen de él y su familia: "Pegué el oído a la ranura y fue entonces cuando por primera vez me enteré de las consejas que sobre mi casa corrían" (Pitol 1959: 67). Así que tenemos a un personaje en cuya perspectiva subjetiva de lo sucedido, se asoma y cobra relevancia la voz del otro, que determina la visión y el discurso real. En resumidas cuentas, el narrador es considerado un loco; éste hace caso omiso a tales consideraciones y se apodera del discurso. Lo que nos recuerda "El corazón delator", considerado un clásico del género gótico, donde el protagonista defiende su cordura y al final se pone en evidencia la locura.

Es en Inglaterra, con la publicación de la novela El castillo de Otranto (1764), de Horace Walpole, que nace el género gótico como reacción al racionalismo de la Ilustración. A partir de ese momento la mayoría de las narraciones del género tendrán como escenario viejos castillos y ruinas medievales. En el caso de "Victorio Ferri cuenta un cuento", si bien no es una edificación medieval guarda muchas semejanzas. El narrador vive en la hacienda el Refugio, propiedad del padre y que ha sido heredada por generaciones. Las haciendas mexicanas comprenden vastas extensiones de tierra, cuya edificación principal es un magnifico caserón de grandes proporciones donde habitan los propietarios, llenas de habitaciones. Además están las viviendas de los trabajadores, que en muchos de los casos eran verdaderos esclavos. En todo caso este sistema latifundista, presente en la narración, donde el hacendado era dueño y señor de vidas, es similar al feudo medieval y su jerarquía.

El narrador da cuenta de las viviendas de los peones describiéndolas como chozas, lo que habla del mísero estado en que vivían. La legitimidad sanguínea sobre la propiedad y el ejercicio del poder no queda a duda. Dice el narrador: "Mi padre ha seguido la obra de su padre, y cuando a su vez él desaparezca yo seré el señor de la comarca" (Pitol 1959: 64). Y dentro de este gran espacio, Victorio Ferri, narra desde el cuarto al que ha sido confinado por su enfermedad, parecido a un calabozo, torre o sótano. Dice en tiempo presente:

En estos días, la enfermedad me ha llevado a rasgar más de un velo hasta ahora intocado. A pesar de haber dormido siempre en este cuarto, puede decirse que apenas ahora me entrega sus secretos. Nunca había, por ejemplo, reparado en que son diez las vigas que corren al través del techo, ni que en la pared de enfrente a la cual yazgo hay dos grandes manchas producidas por la humedad, ni en que, y este descuido me parece imperdonable, bajo la pesada cómoda de caoba anidaran en tal profusión los ratones (Pitol 1959: 66).

\footnotetext{
${ }^{8}$ En el caso de Victorio Ferri: "la hipótesis de una postura anti-dialógica del narrador cobra fuerza gracias a la oposición que se establece entre lo que él afirma conocer y las cosas que los 'otros' supuestamente imaginan de él. Esta polémica se magnifica en pos de la triple repetición del verbo 'sé' en las oraciones iniciales, una redundancia que, como un remolino, arrasa con las injuriosas opiniones de los demás. La debilidad de las afirmaciones ajenas se amplifica a raíz del valor abstracto del verbo 'creer' que, conjugado a la tercera persona plural (y carente de un sujeto explícito), parece sugerir que esos rumores solo son chismes pueblerinos faltos de todo fundamento. Lo mismo sucede con la alusión de Victorio a que, por su habilidad de captar (sugerida por los verbos 'oír', 'decir' y 'hablar'), él ya está al corriente de tales habladurías, es decir, se ha apropiado de ellas y, por ende, puede reprimirlas cuando más se le antoje” (Pace 2017: 266).

9 "En la focalización interna el foyer del relato coincide con una mente figural; es decir, el narrador restringe su libertad con objeto de seleccionar únicamente la información narrativa que dejan entrever las limitaciones cognoscitivas perceptuales y espaciotemporales de esa mente figural" (Pimentel 2005: 99).
} 


\section{Aquí cobra validez lo señalado por María Teresa Zubiaurre:}

El espacio, dotado de un fuerte contenido semántico, habla indirectamente de los personajes y contribuye, metonímicamente a su definición. [...] Una vez que el espacio se empapa de significado simbólico, éste, por así decirlo, se independiza y, al alejarse de lo que sería el mero diseño de un escenario, queda convertido en 'metalenguaje (2000: 22).

Así vemos que el espacio se ajusta en gran medida al que ocupaban las narraciones góticas tradicionales.

Dos elementos de gran importancia son el misterio y el suspenso que se infunde en este tipo de narraciones. El misterio lo entendemos como algo difícil de comprender, que resulta extraño e inexplicable. El suspenso mantiene al lector en la expectativa de lo que va a suceder. Desde un inicio ambos elementos se hacen presentes a partir de la presentación que hace el narrador de sí mismo, que aunque considera una insensatez el que lo crean loco, afirma que es diferente a los demás, al igual que su padre, hermana y primo. A través del monólogo va introduciendo al lector en el mundo interior de sus pensamientos, reflexiones sobre él y lo que lo rodea.

A lo largo de la narración nos encontramos con eventos de difícil explicación, que lindan con lo sobrenatural y que no tienen explicaciones racionales, lo que los dota de misterio y crean la atmósfera de suspenso por la expectativa que van creando. De pronto irrumpe en el relato la frase: "cada mañana, al amanecer, cuando yo regreso a casa" (Pitol 1959: 65). Lo que nos habla de una acción persistente, y surge la pregunta ¿qué hace durante las noches? Más adelante, el tiempo cambia a un pretérito: "La añoranza a cada momento más intensa, de mis correrías nocturnas es constante" (1959: 67). Vuelve al tiempo presente y descubre lo que para nosotros es un misterio: el poder de su invisibilidad: "Sólo yo soy conocido de los perros, de los caballos, de los animales domésticos, puedo acercarme a las chozas a escuchar lo que el peonaje murmura sin obtener ladrido, el cacareo o el relincho con que tales animales denunciarían a cualquier otro" (1959: 67). Misterio y suspenso van en aumento cuando Victorio Ferri habla de las capacidades que ha conseguido con el tiempo:

[...] he sumado conocimientos que no por serme naturales dejan de parecerme prodigiosos: he logrado ver a través de la noche más oscura; mi oído se ha vuelto tan fino como lo puede ser la nutria; camino tan sigilosa, tan, si se puede decir aladamente, que una ardilla envidiaría mis pasos; puedo tenderme en los tejados de los jacales y permanecer allí durante larguísimos ratos hasta escuchar las frases que más tarde repetirá mi boca (Pitol 1959: 68).

Indudablemente estos que llama "conocimientos", son el entrenamiento o pertenencia de los sentidos en extremo agudos, que mucho tienen que ver con lo sobrenatural, ya que más bien podrían corresponder a una combinación de los sentidos de algunos animales. De nuevo el narrador se emparenta con el narrador anónimo de "El corazón delator", quien dice: "La enfermedad ha agudizado mis sentidos, pero no los ha destruido ni embotado. De todos ellos, el más agudo era el del oído. Yo he escuchado todas las cosas del cielo y de la tierra y muchas del infierno" (Poe 1972: 433). Vemos que los dos comparten una hipersensibilidad fuera de lo habitual y en los dos casos no sabemos si es imaginaria o real.

En ninguno de los dos relatos existen explicaciones racionales paro lo que ellos asumen parte de su naturaleza con toda naturalidad, pero en el lector producen una expectativa por descubrir la verdad de lo que ocurre o el desenlace que esto conllevará, además de la fascinación por el misterio que encubre la personalidad de estos extraños personajes, aumentando la atmósfera de suspenso. Así que en estos elementos también se conjuga otro característico de la literatura gótica: eventos de difícil explicación y presencia de lo sobrenatural sin explicación racional.

En El castillo de Otranto el príncipe Manfredo inaugura el arquetipo del villano en la literatura gótica. Tras la muerte de su hijo Conrado el día de su boda, se transforma en un tirano. Todo como consecuencia de la maldición que acarrean, cuyo origen proviene desde tiempos pretéritos a causa de la usurpación del poder que el abuelo hizo sobre los legítimos dueños y señores del castillo. En el caso de "Victorio Ferri cuenta un cuento", se funden dos características del género: la figura tiránica y la presencia del demonio. Al mostrar los rasgos de su identidad, Victorio lo hace de la siguiente manera:

He oído comentar que mi padre es el demonio y aunque hasta ahora jamás haya llegado a descubrirle ningún signo externo que lo identifique como tal, mi convicción de que es lo que es se ha vuelto indestructible. No obstante que en ocasiones me enorgullece, en general ni me place ni me amedrenta el hecho de formar parte de la progenie del maligno (Pitol 1959: 63). 
En este párrafo vemos que en primer término está el otro, en este caso se refiere a los pobladores de la comarca, para quienes el padre encarna al demonio; en segundo, afirma que pese a que no le conste, está seguro sin que quepa duda alguna, que su padre es el demonio, y por último, se considera legítimo heredero de tal condición.

La tiranía del padre se pone de manifiesto en las acciones que comete en contra de los trabajadores de la hacienda. Victorio da cuenta de ello con detalles:

La perversidad de mi padre de tanto prodigarse me fatiga; le he visto el placer en los ojos al ordenar el encierro de algún peón en los cuartos oscuros del fondo de la casa. Cuando los hace golpear y contempla la sangre que mana de sus espaldas laceradas muestra los dientes con expresión de júbilo. Es el único en la hacienda que sabe reír así, aunque también yo estoy aprendiendo a hacerlo (Pitol 1959: 64).

Al igual que el príncipe Manfredo, los Ferri no pueden evitar las consecuencias que traen consigo por ser parte de un linaje que asume su destino como algo irrevocable. Victorio dice: "Mi padre ha seguido la obra de su padre, y cuando a su vez él desaparezca yo seré el señor de la comarca: Me convertiré en el demonio: seré el azote, el fuego y el castigo" (Pitol 1959: 64). Aquí vemos como el villano y el demonio encarnan en una misma persona, en el dueño de la hacienda. Así queda representada la figura masculina tiránica por un noble maligno, cultivada en el género gótico.

Otro de los aspectos del género gótico es el llamado erotismo larvado, es decir oculto y que produce sentimientos prohibidos. En el relato de Sergio Pitol, el protagonista dice:

A veces, sólo por entretenerme, voy a espiar a la choza de Jesusa. Me ha sido dado contemplar cómo su duro cuerpecito se entreteje con la vejez de mi padre. La lubricidad de sus contorsiones me trastorna. Me digo, muy para mis adentros, que la ternura de Jesusa debía dirigirse a mí, ya que somos de la misma edad, y no con el maligno, que hace mucho cumplió los setenta (1959: 69).

De lo anterior inferimos que Jesusa debe ser una mujer apenas entrada la adolescencia, que no obstante su corta edad goza de su sexualidad, y por los deseos de Victorio, por ocupar el lugar del padre y poseer el cuerpo de la chica, que ya tiene desarrollado su instinto sexual. Pero se trata de un erotismo fuera de las convenciones, ya que Jesusa es una mujer más, que forma parte de la servidumbre, y por tal motivo su cuerpo sea utilizado por el dueño de la hacienda como un objeto más de su propiedad. En el caso de Victorio, instiga sus deseos eróticos al ir a la choza para observar a su padre y a Jesusa con el propósito de satisfacer sus instintos y su imaginación.

Por otro lado tenemos un personaje reducido a la soledad, en su mente impera el desosiego, la confusión y oscuros sentimientos. Todo lo anterior da como resultado que nos enfrentemos a un personaje cuyas emociones sean dominadas por las agitaciones de su ánimo. Enclaustrado en el cuarto lúgubre, Victorio Ferri tiene como única compañía sus pensamientos convulsos que lo llevan del presente al pasado, o viceversa, sin descontar el futuro. Se convierten en un cúmulo de recuerdos, ideas, reflexiones, temores y sentimientos de soledad y tristeza.

En el abandono en que se encuentra a su mente acuden ideas de incomprensible venganza hacia su hermana: "Estoy seguro de que si yo ahogara a Carla en el río no habría de sentir el menor remordimiento. Tal vez un día, cuando pueda librarme de estas sucias sábanas que nadie, desde que caí enfermo, ha venido a cambiar, lo haga" (Pitol 1959: 66). Ya casi al final de la narración sabemos que sobré él recae la sentencia de muerte: "En varias ocasiones ha estado aquí el doctor. Me examina con pretenciosa inquietud. Se vuelve hacia mi padre y con voz grave y misericordiosa declara que no tengo remedio, que no vale la pena intentar ningún tratamiento y que no hay más que esperar pacientemente la llegada de la muerte" (1959: 69). Finalmente el personaje va siendo vencido por su dramática realidad y devela la angustia de la que es presa.

En el último párrafo del relato, Victorio Ferri parece cobrar conciencia de lo que verdaderamente le ocurre, lo que también le produce un gran desosiego: "Está visto que de entre los muchos infortunios que pueden aquejar al hombre, los peores son los que provienen de la soledad. Siento cómo ésta trata de abatirme, de romperme, de introducirme pensamientos" (Pitol 1959: 69). Pero el discurso entra en desequilibrio cuando refiere lo que hacía apenas un mes anterior donde las mañanas las entregaba al sueño, las tardes a disfrutar del campo y del río, pero el tiempo nocturno se convertía en una pesadumbre: "Durante la noche oía. Me era siempre doloroso pensar, y por eso constantemente evitaba hacerlo" (1959: 70). La gradación va en aumento y regresa al tiempo presente: "Ahora, con frecuencia inusitada se me ocurren cosas 
y eso me aterra. Aunque sé que no voy a morir, que el médico se equivoca [...] Pero cuando solo, triste, al final de un largo día comienzo a pensar, las dudas me acongojan" (1959: 70). Indudablemente el subconsciente inestable de Victorio Ferri se apodera de su frágil salud mental, y ya sin reparos confiesa su estado de tristeza y su dubitativo pensamiento lo lleva a creer que su padre no sólo gozará con su muerte, sino que le producirá alegría librarse de su presencia y de su voz. Las últimas palabras de Victorio y del relato a su cargo son demoledoras al cerrar el monólogo con el inicio del mismo: "Es posible que los que me odian le hayan llevado al convencimiento de mi locura" (Pitol 1959: 70). De nuevo vemos la presencia del otro que ahora cobra mayor fuerza de lo que ya era una versión generalizada, el cual muestra finalmente su verdadera dimensión al pensar que el padre también ya está convencido de su locura. Así, el personaje lleno de confusión psíquica se ajusta al modelo empleado en el género gótico. El relato de Sergio Pitol, al igual que algunos de Poe, ${ }^{10}$ transcurre en la dimensión psicológica, donde el estado de ánimo es el eje de la estructura narrativa.

Las últimas dos líneas del relato son las palabras inscritas en la lápida: "Victorio Ferri. Murió aún niño. Su padre y hermana lo recuerdan con amor" (Pitol 1959: 71). El final, aparentemente cerrado, nos deja llenos de preguntas, entre otras ¿qué enfermedad tenía, de qué murió, estaba loco? Pero una que llama la atención, es la falta de la madre aún en la lápida donde no aparece el apellido materno. No sólo Victorio nunca la nombra, siendo un hecho que la conoció, ya que su hermana es menor que él, sino también quien hizo mandar hacer la inscripción. De tal suerte que la madre se convierte en el fantasma de la narración, dotándola de mayor misterio y significación de acuerdo con lo señalado por Piglia. Así, la madre, jamás nombrada, adquiere uno de los enigmas más perturbadores del relato.

Como hemos visto, Sergio Pitol, escribió su primer cuento recluido voluntariamente en Tepoztlán, en el cual se va a impregnar el subconsciente de la reciente ruptura amorosa, así como las historias de la abuela y los recuerdos propios, para crear la verdadera historia, la literaria, en un cuento que reúne las características del género gótico que lo emparenta con Poe y Borges.

\section{Referencias bibliográficas}

Beristáin, Helena (1995). Diccionario de Retórica y Poética. México: Editorial Porrúa.

Borges, Jorge Luis (1962), "La casa de Asterión”, en El Aleph. Buenos Aires: Emecé.

Fuentes Rodríguez, César (2007). Mundo Gótico. Barcelona: Editorial Quarentena.

Herrera, Jorge Luis (2009). Voces en espiral. Entrevistas con escritores mexicanos contemporáneos. México: Universidad Veracruzana.

Montelongo, Alfonso (2010), "La locura está en los ojos de quien la mira: los personajes de Sergio Pitol”, Valenciana 6, pp. 91-108.

Muñoz, Mario (1994), "Infierno de todos: formalización de un sistema", en José Eduardo Serrato y Alberto Vital (eds.). Tiempo cerrado, tiempo abierto. Sergio Pitol ante la crítica. México: Coordinación de Difusión Cultural/Dirección de Literatura/Universidad Nacional Autónoma de México/Era, pp. 98-112.

Muñoz, Mario (2007), "Los cuentos de juventud", en Teresa García Díaz (ed.). Victorio Ferri se hizo mago en Viena. Sobre Sergio Pitol. México: Universidad Veracruzana.

Muñoz Rengel, Juan Jacinto (1999), "El influjo de la locura en los estilos literarios de Poe, Maupassant y Nietzsche", Letralia 64.

Disponible en: https://letralia.com/64/en02-064.htm

Pace, Ricardo (2017), “Antidialogismo en 'Victorio Ferri cuenta un cuento', un relato de iniciación de Sergio Pitol”, Románica Olumucensia 29 (2), pp. 259-270. Doi: 10.5507/ro.2017.019

Piglia, Ricardo (2000). Formas breves. Barcelona: Anagrama.

Pimentel, Luz Aurora (2005). El relato en perspectiva. México: UNAM/Siglo XXI.

Pitol, Sergio (1959), "Victorio Ferri cuenta un cuento", en Tiempo cercado. México: Estaciones.

Poe, Edgar Allan (1972), "El corazón delator", en Historias extraordinarias. Trad. Juan Piñeiro. España: Editorial Bruguera.

"Truman Capote" (1982). El oficio del escritor. México: Era.

Vargas Llosa, Mario (1982), "Las mentiras verdaderas", en La señorita de Tacna. México: Seix Barral.

Zubiaurre, María Teresa (2000). El espacio en la novela realista. México: Fondo de Cultura Económica.

\footnotetext{
${ }^{10}$ Para describir sus mundos interiores Poe se acoge a la primera persona, desde la que los protagonistas de sus historias nos trasmiten sus pensamientos tal cual son, sin la mediación de la figura de un narrador. Para dar veracidad a los pensamientos enajenados Poe elige frases cortas, agresivas, rabiosas, de talante nervioso; su estilo por lo tanto es poco recargado, la adjetivación es la justa y las oraciones no se entretienen en ejercicios retóricos o poéticos (Muñoz Rengel 1999).
} 